\#020 Distração osteogénica em fendas palatinas: uma série de casos

Anabela Paula*, Inês Alexandre Neves Francisco, Margarida Mesquita, Isabel Amado, Francisco Do Vale

Instituto de Ortodontia - Faculdade de Medicina da Universidade de Coimbra; Serviço de Cirurgia Maxilo-facial - Centro Hospitalar e Universitário de Coimbra

Introdução: A fenda labiopalatina é uma malformação anatómica congênita com várias co-morbilidades associadas, nomeadamente dificuldades na alimentação, fala e audição, bem como problemas psicossociais. O tratamento gold-standart para o encerramento da fenda palatina é o enxerto ósseo através de osso autólogo com origem na crista ilíaca. No entanto, quando o defeito da fenda apresenta grandes dimensões ou a disponibilidade de tecidos moles circunjacentes é insuficiente, pode ser considerada a distração osteogénica por transporte ósseo alveolar. Este procedimento baseia-se na neoformação óssea e formação de tecido mole adjacente após o deslocamento gradual e controlado dos fragmentos ósseos vascularizados. O objetivo deste trabalho é apresentar uma série de casos de fenda palatina em que a distração osteogénica foi realizada com bons resultados. Descrição da série de casos: Apresentamos 3 casos clínicos com idades entre 13 e 21 anos, submetidos a cirurgia de distração óssea por transporte entre a fenda palatina. Os distractores intra-orais ósteo-ancorados (KLS Martin ${ }^{\circledR} \mathrm{LP}$ ) foram colocados distalmente ao 2. ${ }^{\circ}$ prémolar da hemi-arcada da fenda. A ativação da aparatologia decorreu durante 2 semanas $(1 \mathrm{~mm} /$ dia) após o período de latência de 5 dias. $\mathrm{O}$ período de contenção foi de 2 a 3 meses e, posteriormente, os doentes foram submetidos à remoção do distrator e à mecanoterapia para encerramento de espaços. A percentagem de encerramento da fenda palatina foi cerca de $55 \%$, tendo se verificado o acompanhamento do tecido mucoso adjacente às áreas cirúrgicas. Num dos casos ocorreu uma alteração do formato da arcada com uma constrição da hemiarcada sujeita à distração. Discussão e conclusões: A distração osteogénica é um método que permite a regeneração de novo tecido ósseo/mole com a aplicação gradual de tensão de tração nos fragmentos osteotomizados. Esta série de casos demonstrou que a distração osteogênica é uma técnica confiável e previsível. Por um lado, o ganho ósseo pode chegar a mais de $10 \mathrm{~mm}$ sem necessidade de transplante ósseo; e por outro, as co-morbilidades são reduzidas. A qualidade do osso regenerado é equivalente à do osso nativo e compatível com os tratamentos ortodônticos posteriores, e o risco de infecção é extremamente limitado. Assim, a distração osteogênica é uma técnica ortodôntico-cirúrgica ideal para recriar o tecido ausente/perdido na zona estética anterior, como nos casos de fenda palatina.

http://doi.org/10.24873/j.rpemd.2020.12.744

\section{\#021 Lipoma da cavidade oral: um caso clínico}

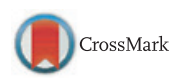

Beatriz Dominguez*, Maria Moz Morais, Pedro Dias Ferraz, Maria Inês Borges, Olímpia Delgado, José Pedro Figueiredo

Centro Hospitalar e Universitário de Coimbra

Introdução: O lipoma é um tumor benigno de tecido adiposo e é a neoplasia mesenquimatosa mais comum do corpo humano, com 15-20\% dos casos localizados na região da cabeça e pescoço, mas apenas 1-4\% envolvendo a cavidade oral. Foi reportado pela primeira vez em 1848, por Roux, como uma 'epúlide amarela'. Os lipomas são tumores de crescimento benigno lento, submucosos, apresentando uma superfície lisa e coloração amarelada, sésseis ou pedunculados. Descrição caso clínico: Doente do sexo feminino de 39 anos, referenciada para o Serviço de Estomatologia do Centro Hospitalar e Universitário de Coimbra por apresentar uma tumefação indolor na língua, com cerca de 2 meses de evolução e crescimento progressivo, que interfere com a mastigação e a fala. Sem quaisquer antecedentes patológicos relevantes. Ao exame objetivo apresenta lesão séssil na região lateral esquerda da língua, junto à sua base, com aproximadamente $2 \mathrm{~cm}$ de maior diâmetro, de aspeto liso e coloração amarelada, mole e indolor à palpação. Não se observam outras alterações de relevo. Sob anestesia local, foi realizada biópsia excisional da lesão: através de incisão longitudinal da mucosa superficial, com bisturi frio (lâmina n. ${ }^{15}$ ), que expôs uma massa amarelada e regular, facilmente individualizada através de dissecção romba, permitindo uma resseção completa da mesma. A análise anatomo-patológica revelou tratar-se de uma massa de tecido adiposo maduro com septos hialinos delgados, parcialmente capsulado compatível com o diagnóstico de lipoma. Foram marcadas consultas subsequentes para remoção da sutura e vigilância. Discussão e conclusões: O lipoma intra-oral pode ocorrer em qualquer localização, sendo incomum na língua, pavimento oral e lábios. Clinicamente apresenta-se como uma massa assintomática, de coloração amarelada. Apesar desta apresentação característica, o seu diagnóstico diferencial inclui outras lesões benignas como fibroma traumático, tumor de células granulares, quisto dermóide, quisto epidermóide, quisto linfoepitelial ou mucocelo, pelo que a sua avaliação anatomo-patológica não pode ser subestimada. O tratamento standard destas lesões consiste na sua excisão cirúrgica, sendo a sua recidiva rara e não estando descritos casos de transformação maligna.

http://doi.org/10.24873/j.rpemd.2020.12.745

\#022 Expansão maxilar em doentes portadores de fenda lábio palatina

Filipa Silva Marques*, Inês Francisco, Anabela Pedroso, Isabel Amado, Margarida Mesquita, Francisco Vale

Centro Hospitalar e Universitário de Coimbra Portugal; Instituto de Ortodontia Faculdade de Medicina da Universidade de Coimbra

Introdução: O tratamento dos doentes portadores de fenda lábio palatina inicia-se na primeira infância com a reparação cirúrgica do defeito do lábio e/ou palato, melhorando a função e a estética facial. No entanto, os processos cicatriciais que advêm destas cirurgias apresentam algumas sequelas como o colapso ântero-posterior e transversal do maxilar. Assim, para estes doentes está preconizado a expansão maxilar para correção da discrepância transversal, idealmente antes da cirurgia de enxerto ósseo. Este trabalho pretende apresentar um caso clínico de um doente portador de fenda 
lábio palatina submetido a expansão lenta maxilar. Descrição do caso clínico: Doente do sexo feminino, 15 anos de idade, apresentou-se à consulta do Instituto de Ortodontia da Faculdade de Medicina da Universidade de Coimbra para correção da má oclusão associada à fenda lábio-palatina esquerda. A doente foi submetida a queiloplastia aos 4 meses e a uranoplastia aos 3 anos de idade. À observação intra-oral, apresentava: classe I de angle à direita e classe II à esquerda; mordida cruzada posterior esquerda; agenesia do 22; e apinhamento anterior na arcada inferior. O plano de tratamento consistiu num aparelho expansor (quad-helix), seguido de enxerto ósseo secundário e, posteriormente aparatologia fixa multibrackets roth 0,18 . Discussão e conclusões: A expansão maxilar contribui para o aumento da largura da cavidade nasal, do maxilar e, consequentemente da fenda palatina. O protocolo de expansão rápida e lenta são ambos eficazes no tratamento da discrepância transversal em doentes portadores de fenda lábio palatina. No entanto, o protocolo de expansão lenta preconiza forças mais leves e contínuas, o que permite uma maior integridade sutural durante a expansão, menor dano e hemorragia, desprogramação da postura e resultados mais estáveis a longo prazo. Estes fatores possibilitam uma terapêutica mais cómoda e menos dolorosa para os doentes. Em doentes portadores de fenda lábio palatina, a escolha pela expansão maxilar lenta, permite uma expansão mais fisiológica, evitando a necrose/dano dos tecidos adjacentes à região da fenda.

http://doi.org/10.24873/j.rpemd.2020.12.746

\section{\#023 Lipoma da cavidade oral- A propósito de um caso clínico}

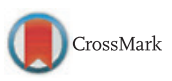

Carina Pires Gonçalves*, Eduardo Simões Ventura, Hugo Martins Marques, Sílvia Dionísio, Nuno Durão, Miguel Vicente

\section{Centro Hospitalar e Universitário do Porto}

Introdução: Lipomas são os tumores benignos mesenquimais mais comuns, compostos de adipócitos maduros. São frequentes na região de cabeça e pescoço, mas raros na cavidade oral, representando $1 \%$ a $4 \%$ das lesões benignas nesta cavidade. A mucosa jugal é a localização mais habitual. Apresentam maior incidência no sexo feminino e entre a $4 .^{\circ}$ e a 7. ${ }^{\circ}$ década de vida. A sua etiologia é idiopática. O lipoma simples e o fibrolipoma, são as variantes histopatológicas mais comuns, na cavidade oral. Descrição do caso clínico: Doente do sexo masculino, com 49 anos, é referenciado à consulta externa de Cirurgia Maxilo-Facial, por massa na região mandibular direita, com crescimento progressivo ao longo de 2 anos. O doente apresenta ao exame objetivo apenas abaulamento da mucosa jugal direita. Esta massa é unitária e séssil, indolor, consistência elástica e infiltração profunda à palpação, com $6-7 \mathrm{cms}$ de diâmetro e de limites bem definidos. Foi realizada ecografia e TC maxilo-facial, com posterior excisão total da lesão, via endobucal, sem intercorrências. O exame anatomopatológico estabeleceu o diagnóstico definitivo de lipoma simples. O doente não apresenta danos morfológicos, funcionais ou recidiva. Discussão e conclusões: Perante os dados epidemiológicos, o quadro clínico e as características da lesão, o diagnóstico a ser colocado é de lipoma. No entanto, há que equacionar outros diagnósticos, dada a profundidade da lesão, como: fibroma, tumor de células granulares, neoplasia de glândulas salivares, quisto dermoide, quisto linfoepitelial oral e outros tumores benignos dos tecidos moles. O diagnóstico de lipoma é clínico sendo o diagnóstico definitivo estabelecido pelo exame anatomopatólogico. Esta hipótese diagnóstica é sustentada por o quadro clínico ser insidioso e por esta lesão ser unitária, mole, indolor e com crescimento lento. Apesar dos lipomas poderem ocorrer em todas idades, são mais frequentes entre a $4 .^{\circ}$ e a $7 .^{\circ}$ década de vida, o que apoia esta hipótese. Também a localização da lesão, corrobora a hipótese de lipoma, porque, apesar de poderem ser encontrados em várias localizações (lábio inferior, região retromolar, língua, pavimento, palato), a mucosa jugal é a localização mais frequente. Apesar do crescimento dos lipomas orais ser limitado, podem atingir grandes dimensões, o que pode interferir com a fala e a mastigação havendo a necessidade de tratamento. A excisão cirúrgica simples é o tratamento de eleição, sendo a recidiva e a transformação maligna raras.

http://doi.org/10.24873/j.rpemd.2020.12.747

\section{\#024 Eritroleucoplasia - a propósito de um caso clínico}

Olga Vascan*, Maria J. Morais, Ana M. Marques, João M. Oliveira, Francisco J. D. Marques, José P. Figueiredo

Serviço de Estomatologia - Centro Hospitalar e Universitário de Coimbra; Serviço de Cirurgia Maxilo-Facial - Centro Hospitalar e Universitário de Coimbra

Introdução: Eritroleucoplasia é definida pela OMS como uma placa ou mancha branca e vermelha que não corresponde clínica ou histologicamente a nenhuma doença conhecida". É uma lesão oral rara, de etiologia desconhecida, em que o tabaco, o álcool e a nutrição, combinados ou não, parecem ser factores predisponentes. A taxa de malignização varia consoante os estudos, sendo reportados valores entre $5,2 \%$ e $55 \%$, com taxas mais elevadas nos não fumadores. Localiza-se com mais frequência na língua, comissuras labiais e pavimento bucal, podendo ou não estar associada a dor ou disfagia. Descrição do caso clínico: Senhora de 62 anos, observada na consulta externa Serviço de Estomatologia por lesão leuco-eritematosa da língua com cerca de 6 meses de evolução, indolor. Sem antecedentes pessoais e familiares relevantes. Ao exame clínico, observou-se placa leuco-eritroplásica no bordo esquerdo da língua, textura rugosa, de consistência mole, depressível, não infiltrada com cerca de 4,5 x $3 \mathrm{~cm}$. Na primeira consulta, com base na história clínica e exame objetivo estabelece-se um diagnóstico clínico de eritroleucoplasia. Foi explicada a situação à doente e procedeu-se a um desgaste selectivo dos dentes contíguos para eliminar qualquer traumatismo. Após 3 semanas, marcou-se consulta de reavaliação, não se observou regresssão da lesão. Foi decidido realizar biopsia excisional da lesão, e envio da peça para estudo anatomo-patológico. O re- 